\title{
Estimation of the Monthly Global, Direct, and Diffuse Solar Radiation in Japan Using Artificial Neural Network
}

\author{
Adi Kurniawan and Eiji Shintaku
}

\begin{abstract}
In order to obtain the optimal design of solar energy system, the data of solar radiation should be provided. In this study, an estimation model of monthly solar radiation in Japan is developed using artificial neural network (ANN). The purpose of this study is to provide an accurate model to estimate the solar radiation, especially for the location where measured data is not available. The structure of ANN is constructed using geographical and 6 years-meteorological data between 2011-2016. The model has been validated by comparing the estimation results with measured solar radiation data on five different stations in 2017. Considering relatively small mean absolute percentage error (MAPE) and root mean square error (RMSE), it is believed that the proposed model could accurately predict the monthly solar radiation, which further could be used to obtain optimal design of solar energy system in Japan.
\end{abstract}

Index Terms-Artificial neural network, Japan, meteorological data, solar radiation estimation.

\section{INTRODUCTION}

Recently, the use of solar energy systems has been grown quickly in Japan. The electrical energy produced by solar energy systems rose from $2.7 \%$ in 2015 to $4.3 \%$ in 2016 , whereas all renewable energy resources contribute to $14.2 \%$ of total electrical energy [1]. As the effort to suppress the increasing of air pollution, the utilizing of clean renewable energy should be encouraged [2], [3]. Among others, solar energy is one of the most preferable due to its availability in all places [4].

While the solar energy is clean and abundant, the equipment to convert it into the electric energy is costly. Not only the solar panel itself, but also battery as the energy storage and electric converter as the power stabilizer need to be counted. The optimization in both of design and operation need to be performed so that its energy price can compete with fossil fuel generator or other renewable energy system. Many researches have been done in order to optimize the system design such as optimal sizing of the panel and battery [5], [6] and optimal tilt angle [7], [8]. Meanwhile, the researches in optimal operation are performed in the form of

Manuscript received August 7, 2019; revised January 12, 2020. This work was supported in part by Hitachi Global Foundation.

A. Kurniawan is with the Department of Marine Engineering, Institu Teknologi Sepuluh Nopember, Surabaya 60111 Indonesia. Currently, he is also with the Department of Transportation and Environmental Systems, Hiroshima University, Higashi-Hiroshima 739-8511 Japan (e-mail: adi.kurniawan@ne.its.ac.id).

E. Shintaku is with the Department of Transportation and Environmental Systems, Hiroshima University, Higashi-Hiroshima 739-8511 Japan (email: eshin@hiroshima-u.ac.jp). optimal energy conversion [9], optimal battery charging control [10], and optimal connection to the electric bus [11].

In order to obtain the optimal design and control of the solar energy system, the long terms information regarding the solar radiation data is necessary. However, since the measurement of solar radiation is not easy due to the high price and difficult maintenance and calibration of the equipment, the data is available only in limited number of places. To overcome the limitation of the data, an accurate estimation can be used as the replacement.

Several methods have been developed to estimate the amount of solar radiation in one location. Among empirical models, the Angstrom-Prescott model and its modifications are widely popular. The model is based on linear and nonlinear regression and mainly uses the data of sunshine duration and clear sky radiation data [12]. Several modifications of this method revolve around the selection of input variables and the regression form [13].

Recently, the artificial intelligence methods are also intensively developed to estimate the amount of solar radiation. Artificial neural network (ANN) which previously has been used in solar energy systems as a maximum power point tracker [14] and load management controller [15], recently is also used to estimate the solar radiation with various input variables. Five input variables consist of latitude, longitude, altitude, month of the year, and mean cloudiness are used to estimate solar radiation in several cities in Turkey [16]. Meanwhile, six variables are used to predict solar radiation in China [17]. Instead of mean cloudiness, daily mean temperature and sunshine duration are used. Several combinations of input has been investigated to estimate the global solar radiation in Morocco [18]. The results show that the best configuration consist of seven inputs with the addition of relative humidity compared with [17]. While the minimum number of inputs might be preferred due to its simplicity, higher number of possibly related input can produce higher accuracy of solar radiation estimation.

The comparison between linear, nonlinear regression, fuzzy logic, and ANN to predict the global and diffuse solar radiation in Malaysia has been performed in [19]. The result shows that ANN gives better estimation compared with other methods due to its computational and generalization capability. The similar comparison was performed in Egypt. Again, ANN estimation model generates smaller error compared with empirical model [20].

To date, there is no research discussed about the long-term prediction of solar radiation in Japan, while the use of solar energy in Japan is continuously increasing. Accordingly, this 
research aims to provide the first and an accurate model to predict the monthly global, direct and diffuse solar radiation in the region of Japan using ANN. While the model can be used to predict the solar radiation in other countries, the analysis in this study is focused on the compatibility of the model with actual measured data in Japan. Further, the estimation data of the solar radiation generates by the proposed model can be utilized as a basis for designing an optimal solar energy system.

The rest of this paper is organized as follows. The concept of the research method proposed in this study is explained in Section II. Graphical and statistical results of the comparison between estimation using the proposed method and the actual data are presented in Section III. The conclusion of this study is shown in Section IV.

\section{RESEARCH METHOD}

This research has been done by collecting the previous data from the Japan Meteorological Agency, then build and validate the ANN through the neural network toolbox in Matlab computer software. The data was taken from 5 stations in Japan, namely Sapporo, Tateno, Fukuoka, Ishigakijima, and Minamitorishima. Those 5 stations can represent the condition on all of Japan because they are spread from the region of north-east (Sapporo, lat. 43.06 long. $141.33^{\circ}$ ), south-east (Minamitorishima, lat. 24.29 , long. $124.16^{\circ}$ ), center (Tateno, lat. $36.06^{\circ}$, long. $140.13^{\circ}$ ), north-west (Fukuoka, lat. $33.58^{\circ}$, long. $130.38^{\circ}$ ), and south-west of Japan (Ishigakijima, lat. 24.34 ${ }^{\circ}$, long. $124.16^{\circ}$ ). While the data of global solar radiation is available on 157 locations, the data of direct and diffuse radiation in Japan is only available on those 5 locations.

The structure of the ANN is shown in Fig. 1. The network consists of 1 input layer, 1 hidden layer, and 1 output layer. The input data for the ANN are latitude; longitude; altitude; number of months; average, minimum, and maximum temperature; sunshine duration; precipitation; wind speed; and relative humidity. Meanwhile, the target output data are direct, diffuse, and global solar radiation. Those 11 input variables were selected due to their easiness to be accessed. While the cloud amount may also affect the amount of direct and diffuse solar radiation, it was ruled out as the input of the ANN in this study as its data is not widely available.

The meteorological data used for the ANN training are the monthly average of 6 years data between 2011-2016. Although the input data is available from the older years, limiting the training data to the current decade is believed to generate higher accuracy because the effect of global warming tend to change the weather climate severely compared with previous decades. Furthermore, the data of direct and diffuse solar radiation in all locations except Tateno is only available since 2010 .

The ANN is trained using Levenberg-Marquardt method, with $70 \%$ of the samples are taken for training, and each $15 \%$ are taken for validation and testing. In this study, the hidden layer consists of 15 hidden nodes. The number of the hidden node is chosen after comparing the global root mean square error (RMSE) from various number of hidden nodes from 5 to 50 which shown in Table 1 . While the RMSE training of 15 hidden layers is not the lowest, it RMSE validation is the second best and it RMSE testing is the lowest. The comparison of the number of the hidden layers is stopped at 50 because the RMSE shows a tendency to increase since 35 hidden layers, particularly indicated for validation and testing process.

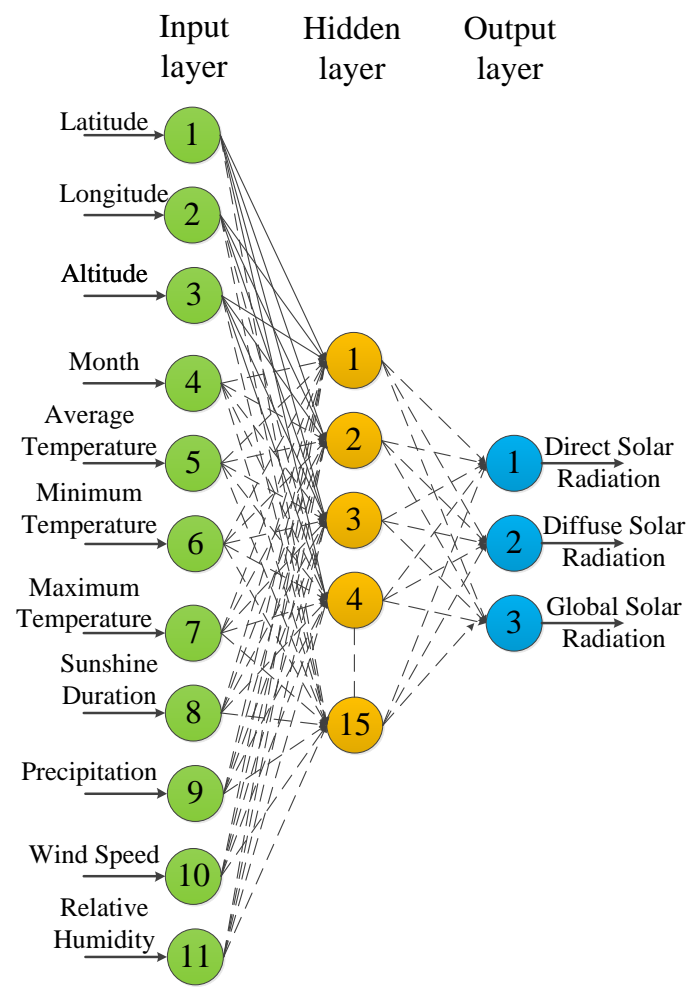

Fig. 1. Architecture of ANN to predict the solar radiation.

TABLE I: COMPARISON OF GLOBAL RMSE FOR VARIOUS NUMBER OF HIDDEN LAYER

\begin{tabular}{llll}
\hline \hline $\begin{array}{l}\text { Number of Hidden } \\
\text { Layer }\end{array}$ & $\begin{array}{l}\text { RMSE } \\
\text { Training }\end{array}$ & $\begin{array}{l}\text { RMSE } \\
\text { Validation }\end{array}$ & $\begin{array}{l}\text { RMSE } \\
\text { Testing }\end{array}$ \\
\hline 5 & 0.368 & 0.528 & 0.649 \\
10 & 0.254 & 0.499 & 0.395 \\
15 & 0.211 & 0.499 & 0.375 \\
20 & 0.242 & 0.617 & 0.443 \\
25 & 0.335 & 0.808 & 0.698 \\
30 & 0.219 & 0.420 & 0.494 \\
35 & 0.152 & 0.597 & 0.681 \\
40 & 0.115 & 0.742 & 0.886 \\
45 & 0.162 & 0.532 & 0.895 \\
50 & 0.196 & 0.795 & 0.831 \\
\hline \hline
\end{tabular}

\section{RESUlTS AND DisCUSSION}

The ANN is trained using monthly aforementioned data from 2011 until 2016. In total, there are 360 samples for each data parameter. The validation is performed by comparing the estimation results from the ANN for the year of 2017 and the measured radiation data of 2017 from the five stations. Three statistic parameters in the form of mean absolute percentage error (MAPE), RMSE, and coefficient of determination $\left(\mathrm{R}^{2}\right)$ are used to measure the accuracy of the estimation results. These three statistic parameters are the most frequently used to measure the accuracy of solar 
radiation prediction using ANN [21]. Each of the mentioned parameters can be calculated as follows

$$
\begin{gathered}
\text { MAPE }=\frac{1}{n} \sum\left|\frac{G_{\text {pred }}-G_{\text {meas }}}{G_{\text {meas }}}\right| \times 100 \% \\
\text { RMSE }=\sqrt{\frac{\sum\left(G_{\text {pred }}-G_{\text {meas }}\right)^{2}}{n}} \\
R^{2}=1-\frac{\sum\left(G_{\text {meas }}-G_{\text {pred }}\right)^{2}}{\sum G_{\text {pred }}^{2}}
\end{gathered}
$$

Smaller percentage of MAPE and RMSE, and larger value of $R^{2}$ indicate that the estimation results are closer to the measured data and that the model can be recommended to be used for the time series prediction.

The graphic of comparison between the estimation of radiation from ANN and the measured radiation from the 5 locations are shown in Fig. 2-Fig. 6, while the statistical results are presented in Table 2 . These figures indicate that there is high agreement between actual measured solar radiation and estimation value.

In Table II, the statistical results are not only from the first 5 locations, but also from 6 other locations including Tokyo. The 6 selected additional locations are also spread around Japan. Tokyo, Osaka, and Hiroshima are close to the center of Japan since they are located in main island. Kumamoto is located in the west of Japan, near of Fukuoka. Meanwhile, Naha is in south-west near Ishigakijima, and Chichihima is in south-east, close to the Minamitorishima. However, for the additional 6 locations, the statistical results are only available for global solar radiation due to the unavailability of the actual direct and diffuse solar radiation data.

TABLE II: STATISTICAL TEST RESULTS OF THE ESTIMATION MODEL FOR VARIOUS LOCATIONS IN JAPAN

\begin{tabular}{lllll}
\hline \hline \multirow{2}{*}{ Station } & Radiation & MAPE $(\%)$ & $\begin{array}{l}\text { RMSE } \\
(\%)\end{array}$ & $\mathrm{R}^{2}$ \\
\hline Sapporo & Direct & 4.85 & 5.27 & 0.997 \\
& Diffuse & 4.15 & 4.90 & 0.998 \\
Tateno & Global & 3.52 & 4.56 & 0.998 \\
& Direct & 5.84 & 7.35 & 0.995 \\
& Diffuse & 4.54 & 5.54 & 0.997 \\
Fukuoka & Global & 3.82 & 4.09 & 0.998 \\
& Direct & 8.11 & 11.15 & 0.987 \\
Ishigakijima & Diffuse & 8.98 & 10.19 & 0.990 \\
& Global & 5.27 & 5.45 & 0.997 \\
Direct & 7.92 & 9.29 & 0.993 \\
Minamitorishima & Diffuse & 6.17 & 7.97 & 0.995 \\
& Global & 3.25 & 3.39 & 0.999 \\
& Direct & 4.76 & 5.52 & 0.997 \\
Tokyo & Diffuse & 4.92 & 6.15 & 0.996 \\
Osaka & Global & 2.61 & 2.82 & 0.999 \\
Hiroshima & Global & 4.85 & 6.17 & 0.997 \\
Kahamoto & Global & 3.06 & 3.09 & 0.999 \\
\hline \hline
\end{tabular}

It can be seen from the Fig. 2-Fig. 6 that the ANN model generates similar number of radiations compared with the real measurement data in 2017, especially for global radiation. For the first 5 locations, the highest MAPE and RMSE percentage are only $5.27 \%$ and $5.45 \%$ for global radiation, $8.11 \%$ and $11.15 \%$ for direct radiation, and lastly $8.98 \%$ and $10.19 \%$ for diffuse radiation. All of the highest errors occur in the data of Fukuoka.

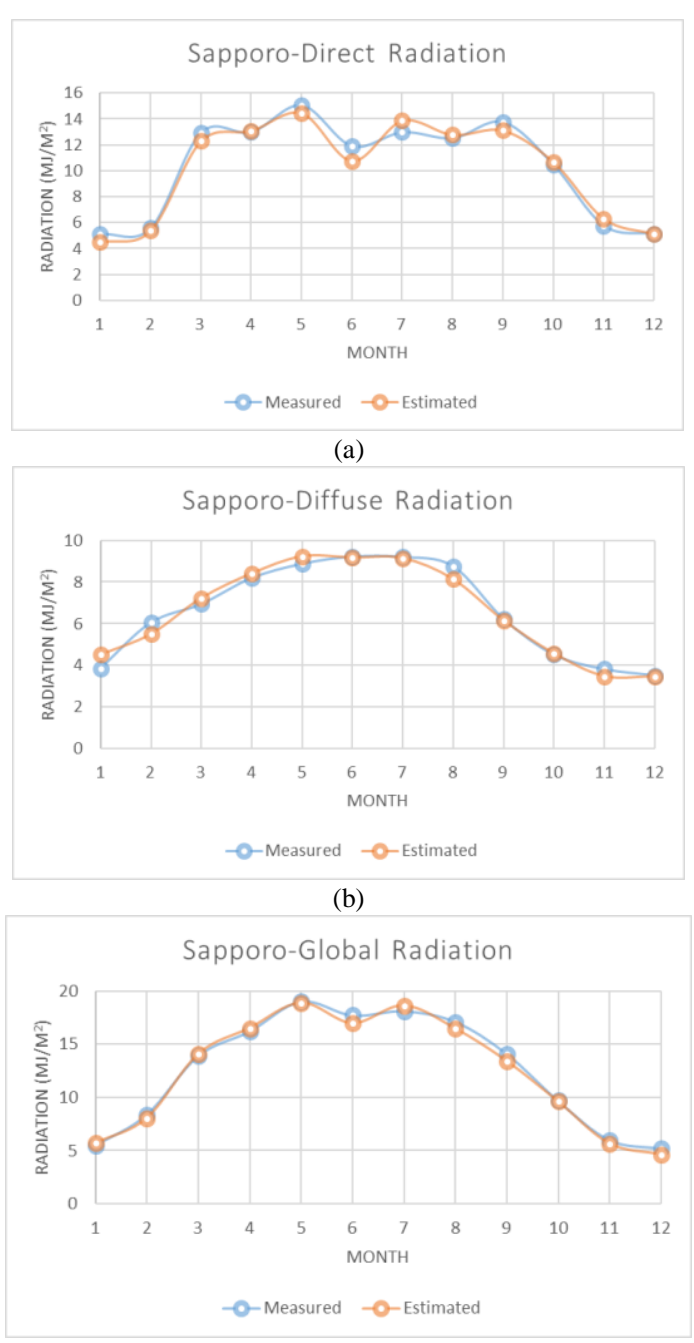

(c)

Fig. 2. Comparison between the estimation and measured radiation on Sapporo (a) Direct radiation (b) Diffuse radiation (c) Global radiation

Based on the results, the errors can be either underestimation or overestimation, even for the same type of solar radiation in the same city. An example is the comparison of diffuse solar radiation in Minamitorishima. In May, the ANN estimated that the diffuse radiation is 7.93 $\mathrm{MJ} / \mathrm{m}^{2}$ or $9.16 \%$ lower than actual data which is $8.73 \mathrm{MJ} / \mathrm{m}^{2}$. On the contrary, In June, the ANN turned out to be overestimated. In this time, the predicted value is $7.18 \mathrm{MJ} / \mathrm{m}^{2}$ whereas the actual value decreases sharply to $6.56 \mathrm{MJ} / \mathrm{m}^{2}$. In this case, the overestimation value is $9.45 \%$. While the positive and negative error caused by overestimation and underestimation may cancel each other in MAPE calculation, it is accumulated in RMSE calculation.

Generally, the error of global radiation for the additional 6 locations are slightly higher compared with the first 5 locations since their data is not included in training process. Both of the RMSE and MAPE for the cities of Hiroshima, Kumamoto, and Naha are higher than $9 \%$. However, in other 
locations such as Tokyo and Osaka, the errors are even smaller than the error in the data of Fukuoka. One of the possible causes is that both of Tokyo and Osaka are located in the main inland and close to Tateno as one of the original ANN training locations. Therefore, the weather condition between these three cities is not far different among others. While Hiroshima also located in main inland, the distance to Tateno is farther and resulting bigger difference in meteorological conditions.

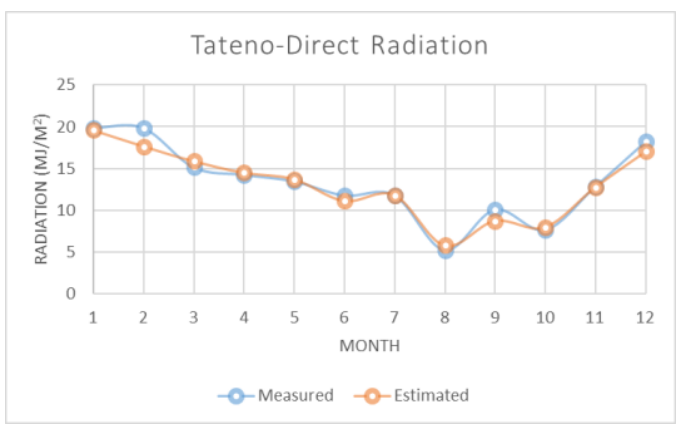

(a)

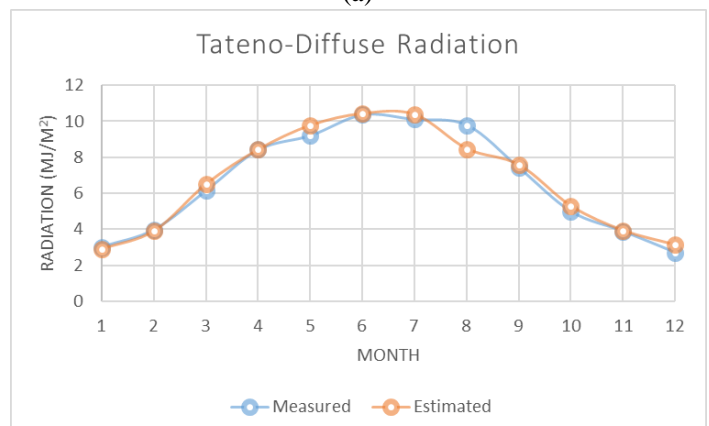

(b)

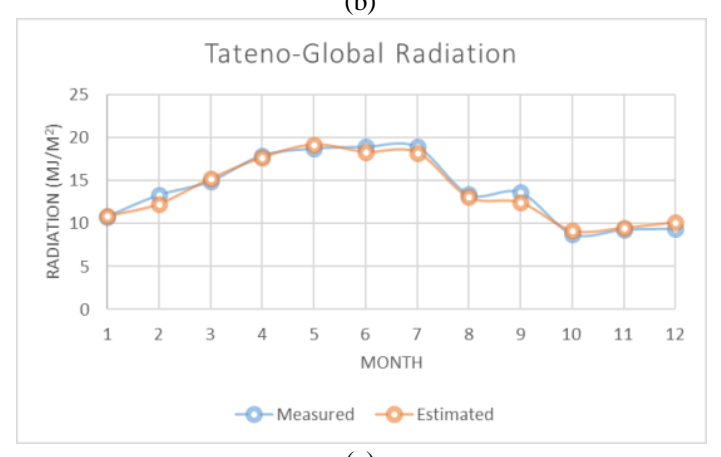

(c)

Fig. 3. Comparison between the estimation and measured radiation on Tateno (a) Direct radiation (b) Diffuse radiation (c) Global radiation.

In order to measure the accuracy of the estimation using the proposed method, a comparison of the statistic parameters with the previous researches is required. Based on [17], the RMSE of global radiation in the cities of China are ranged between $8.2 \%$ to $31.4 \%$. As the highest RMSE revealed in this study is only $11.15 \%$, it can be said that this value is highly acceptable. On the other hand, the MAPE of global radiation in India is $6.89 \%$ [22]. The MAPE of global radiation for some cities such as Hiroshima and Kumamoto achieved in this study are higher but according to Lewis classification of MAPE, the MAPE $\leq 10 \%$ indicates that the prediction is highly accurate, while $10 \% \leq$ MAPE $\leq 20 \%$ suggest good prediction [22]. The only MAPE higher than $10 \%$ comes from the prediction of global solar radiation in Kumamoto. Furthermore, the 0.988 minimum coefficient of determination achieved in this study are similar with 0.984 of similar research performed for the cities in Turkey [23]. It is also stated in [24] that coefficient of determinations higher than 0.82 are considered good enough to estimate the solar radiation using ANN.

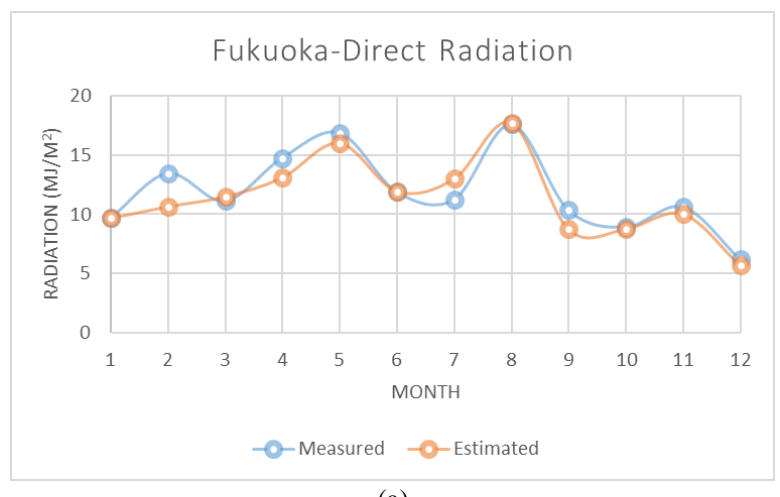

(a)

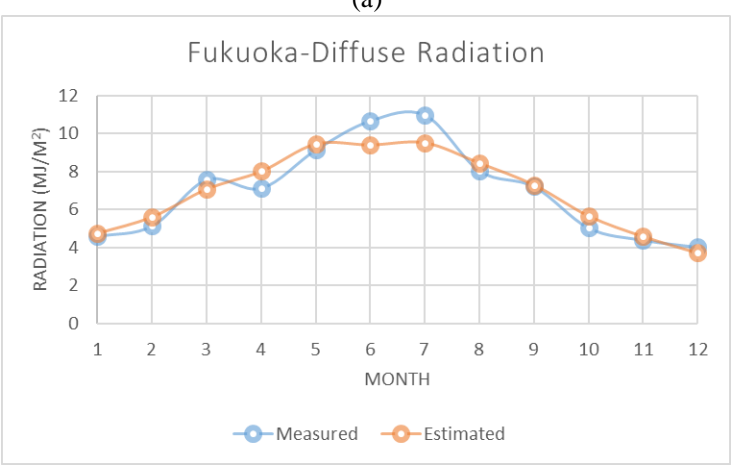

(b)

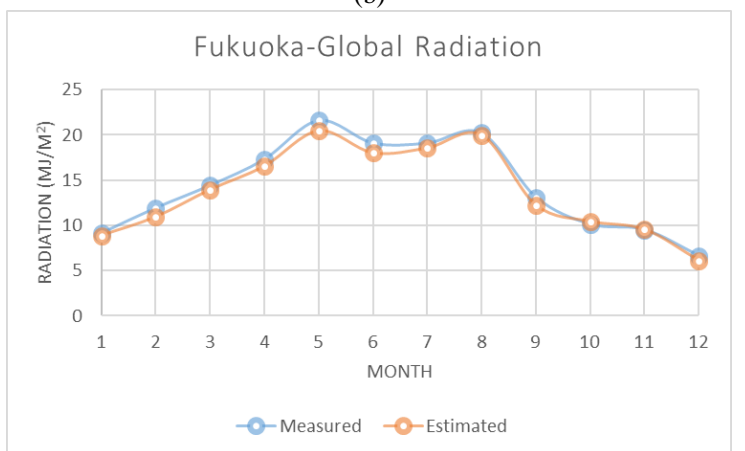

(c)

Fig. 4. Comparison between the estimation and measured radiation on Fukuoka (a) Direct radiation (b) Diffuse radiation (c) Global radiation

Based on the statistical test results of the first 5 locations, the errors in predicting direct and diffuse radiation are always higher than global radiation. However, the difference of error percentage between global, direct, and diffuse radiation both in RMSE and MAPE are considerably small, as they are less than $6 \%$. One of the possible reasons of the higher error from direct and diffuse radiation is that the amount of direct and diffuse radiations are greatly affected by the percentage of cloud in the atmosphere, while this data is not available to be included to construct the ANN in this study. The other possibility is related with the anomaly of the weather condition in the time of measurement. The direct radiation in Fukuoka in February 2017 is given as the example. The difference between estimation and measured value is $2.8 \mathrm{MJ} / \mathrm{m}^{2}$ which is the highest among the others. Comparing with the average data between 2011 and 2016, 
the average temperature in 2017 is only $0.83^{\circ} \mathrm{C}$ or $11.11 \%$ higher. Meanwhile, the sunshine duration and precipitation in 2017 are $36.86 \%$ higher and $41.59 \%$ lower than the previous years. Such as phenomenon may differ the actual value from the prediction.

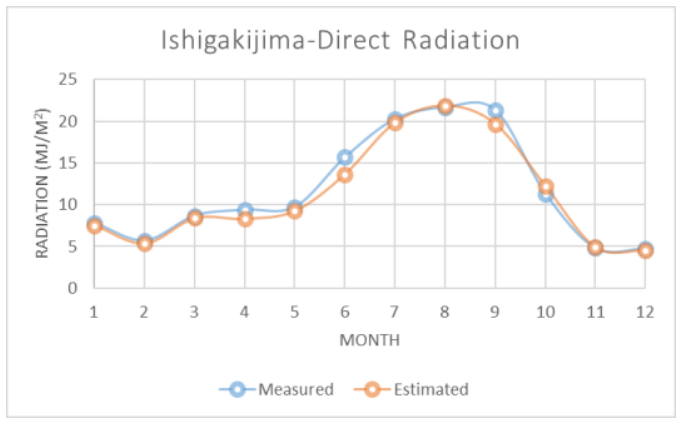

(a)

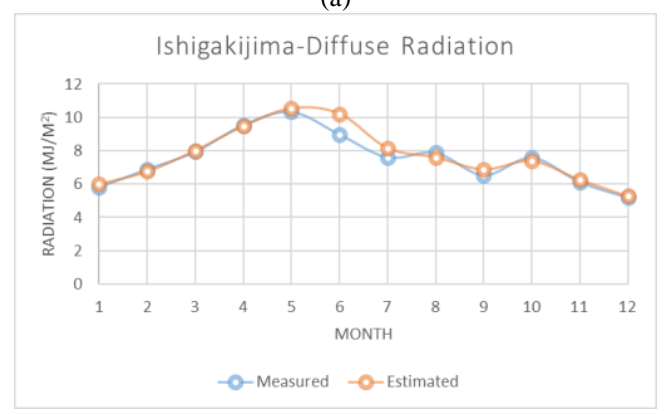

(b)

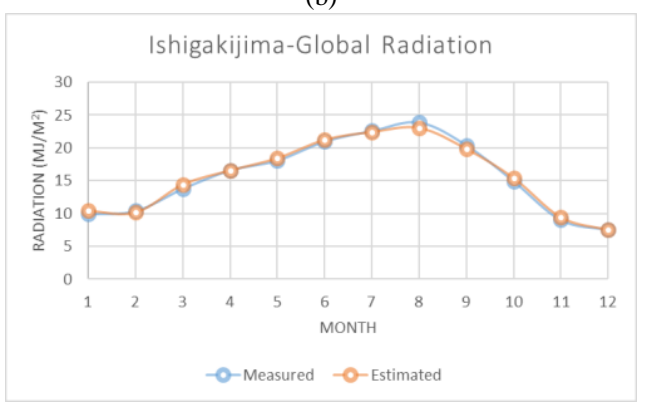

(c)

Fig. 5. Comparison between the estimation and measured radiation on Ishigakijima (a) Direct radiation (b) Diffuse radiation (c) Global radiation.

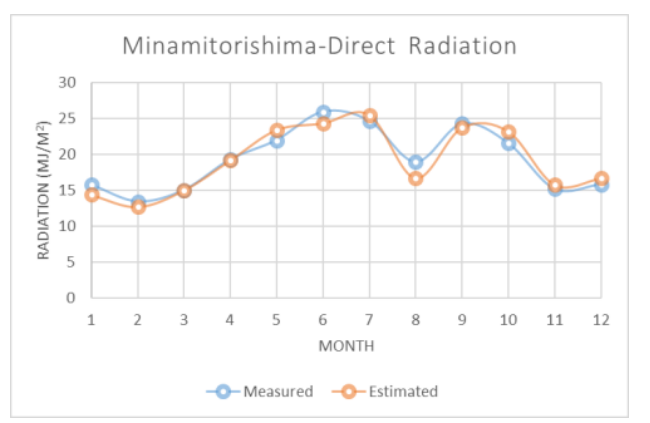

(a)

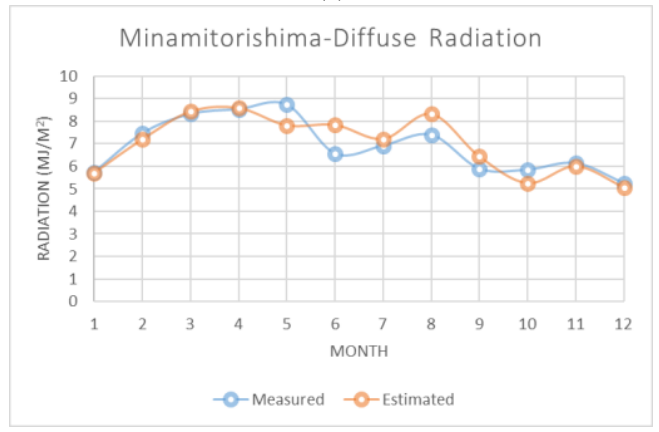

(b)

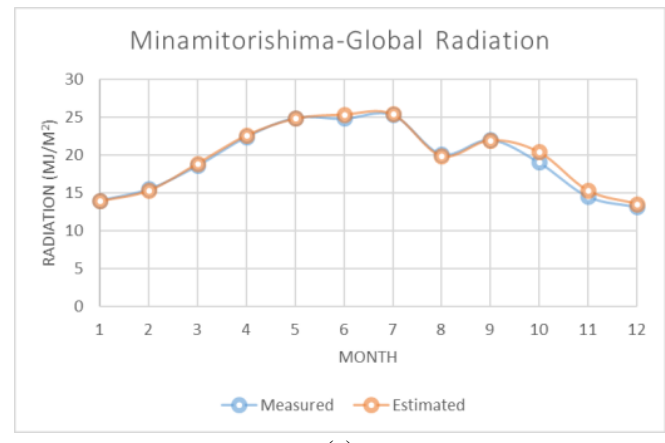

(c)

Fig. 6. Comparison between the estimation and measured radiation on Minamitorishima (a) Direct radiation (b) Diffuse radiation (c) Global radiation

\section{CONCLUSION}

The estimation model of solar radiation has been presented in this study. Compared with previous researches, the model proposed in this study are more detailed since it can be used to predict not only global radiation, but also direct and diffuse radiation. The inputs of the model are the geographical data, time, and basic meteorological data which available for many locations in Japan. Statistical test results from the comparison between the estimation and measured data in 2017 is showing good agreement, both on the 5 locations which data is selected for training the ANN, and the other 6 locations around Japan. Coefficient of determination for all the 11 locations are 0.988 or higher. The results indicate that the model can be used to estimate the amount of any types of solar radiation, especially on the locations where the solar radiation data is not recorded. That being said, an investigation of the weight of each input variable to impact the estimation accuracy needs to be performed in the future. With a priority scale, some input variables which data is difficult to be accessed might be ignored without greatly decrease the estimation accuracy.

\section{APPENDIX}

$G_{\text {pred }}=$ Prediction of solar radiation components

$G_{\text {meas }}=$ Measured solar radiation components

$n \quad=$ Number of data

\section{CONFLICT OF INTEREST}

The authors declare no conflict of interest.

\section{AUTHOR CONTRIBUTIONS}

The first author is tasked with collecting data, doing simulation, and analyzing the result based on simulation. The second author is tasked with guiding, directing, and giving advice during the research.

\section{ACKNOWLEDGMENT}

Authors would like to thank Japan Meteorological Agency for providing the meteorological data used as the input on this research.

\section{REFERENCES}

[1] W. Pentland, Japan's Solar Boom Is Accelerating, Forbes, New York, 
Jan-2017.

[2] A. Kurniawan, F. Adam, S. P. Fitri, and S. Sarwito, "Experimental study of magnesium anode voltaic cell as electrical source of impressed current cathodic protection for ship hull," International Journal of Applied Engineering Research, vol. 11, no. 24, pp. 11647-11650, December 2016.

[3] A. Kurniawan, M. Yosi, I. S. Arief, and D. Cahyagi, "Design of marine cable installation for ocean current power plant in Toyopakeh strait-Bali," in Proc. 2017 Int. Conf. Adv. Mechatronics, Intell. Manuf. Ind. Autom.(ICAMIMIA), 2018, pp. 136-140.

[4] A. Kurniawan, "A review of solar-powered boat development," IPTEK J. Technol. Sci., vol. 27, no. 1, pp. 1-8, April 2016.

[5] S. Wen, D. C. Yu, Q. Fu, Y.-Y. Hong, L. Yu and R. Yang, "Optimal sizing of hybrid energy storage sub-systems in PV/diesel ship power system using frequency analysis," Energy, vol. 140, pp. 198-208, December 2017.

[6] C. Yao, M. Chen, and H. Ying-Yi, "Novel adaptive multi-clustering algorithm-based optimal ESS sizing in ship power system considering uncertainty," IEEE Transactions on Power Systems, vol. 33, no. 1, pp. 307-316, January 2018

[7] M. Guo, H. Zang, S. Gao, T. Chen, J. Xiao, L. Cheng, Z. Wei, and G. Sun, "Optimal tilt angle and orientation of photovoltaic modules using HS algorithm in different climates of China," Applied Sciences, vol. 7, no. 10 pp. 1028-1039, October 2017

[8] H. Zang, M. Guo, Z. Wei, and G. Sun, "Determination of the optimal tilt angle of solar collectors for different climates of China," Sustainability, vol. 8, no. 7, pp. 1-16, July 2016.

[9] A. Kurniawan, E. S. Koenhardono, A. A. Masroeri, S. Sarwito, and A. Santoso, "Optimizing solar-powered tourist boat with converter-based maximum power point tracker," International Journal of Applied Engineering Research, vol. 11, no. 23, pp. 11142-11144, November 2016.

[10] Y. Xing, E. W. M. Ma, K. L. Tsui, and M. Pecht, "Battery management systems in electric and hybrid vehicles," Energies, vol. 4, no. 12, pp. 1840-1857, October 2011.

[11] A. Kurniawan and E. Shintaku, "Control of photovoltaic system connected to DC bus in all-electric ship," in Proc. 2017 Int. Conf. Adv. Mechatronics, Intell. Manuf. Ind. Autom. (ICAMIMIA), 2018, pp. $110-115$.

[12] A. Teke and H. B. Yildirim, "Estimating the monthly global solar radiation for Eastern Mediterranean Region," Energy Convers. Manag., vol. 87, pp. 628-635, August 2014.

[13] K. Bouchouicha, N. Bailek, M. E. S. Mahmoud, J. A. Alonso, A. Slimani, and A. Djaafari, "Estimation of monthly average daily global solar radiation using meteorological-based models in Adrar, Algeria," Applied Solar. Energy, vol. 54, no. 6, pp. 448-455, December 2018.

[14] A. Kurniawan, E. Haryanto, and A. A. Masroeri, "A neural network based maximum power point tracker with KY converter for photovoltaic system on a moving vehicle," in Proc. 2015 Int. Conf. Adv. Mechatronics, Intell. Manuf. Ind. Autom. (ICAMIMIA), 2016, pp. $117-120$.

[15] E. Matallanas et al., "Neural network controller for active demand-side management with PV energy in the residential sector," Applied Energy, vol. 91, no. 1, pp. 90-97, March 2012.

[16] A. Koca, H. F. Oztop, Y. Varol, and G. O. Koca, "Estimation of solar radiation using artificial neural networks with different input parameters for Mediterranean region of Anatolia in Turkey," Expert Systems with Applications, vol. 38, no. 7, pp. 8756-8762, July 2011.

[17] J. C. Lam, K. K. W. Wan, and L. Yang, "Solar radiation modelling using ANNs for different climates in China," Energy Convers. Manag., vol. 49 no. 5, pp. 1080-1090, May 2008.

[18] O. Nait Mensour, S. Bouaddi, B. Abnay, B. Hlimi, and A. Ihlal, "Mapping and estimation of monthly global solar irradiation in different zones in souss-Massa area, Morocco, Using artificial neural networks," International Journal of Photoenergy, vol. 2017, October 2017.

[19] T. Khatib, A. Mohamed, M. Mahmoud, and K. Sopian, "Modeling of daily solar energy on a horizontal surface for five main sites in Malaysia," International Journal of Green Energy, vol. 8, no. 8, pp. 795-819,
November 2011

[20] E. A. Ahmed and M. E.-N. Adam, "Estimate of global solar radiation by using artificial neural network in Qena, upper Egypt," Journal of Clean Energy Technol., vol. 1, no. 2, pp. 148-150, April 2013.

[21] M. Marzouq, H. El Fadili, Z. Lakhliai, and K. Zenkouar, "A review of solar radiation prediction using artificial neural networks," in Proc. 2017 Int. Conf. Wirel. Technol. Embed. Intell. Syst. (WITS), 2017, pp. 337-342.

[22] A. K. Yadav, H. Malik, and S. S. Chandel, "Selection of most relevant input parameters using WEKA for artificial neural network based solar radiation prediction models," Renewable and Sustainable Energy Reviews, vol. 31, pp. 509-519, January 2014.

[23] C. Gurlek and M. Sahin, "Estimation of the global solar radiation with the artificial neural networks for the city of Sivas," European Mechanical Science, vol. 2, no. 2, pp. 46-51, 2018.

[24] M. Marzouq, Z. Bounoua, A. Mechaqrane, H. E. Fadili, Z. Lakhliai, and K. Zenkouar, "ANN-based modelling and prediction of daily global solar irradiation using commonly measured meteorological parameters," in Proc. IOP Conf. Ser. Earth Environ. Sci., June 2018, vol. 161, no. 1.

Copyright $\odot 2020$ by the authors. This is an open access article distributed under the Creative Commons Attribution License which permits unrestricted use, distribution, and reproduction in any medium, provided the original work is properly cited (CC BY 4.0).

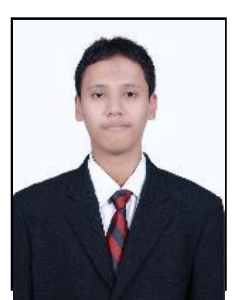

Adi Kurniawan was born in Surabaya, Indonesia in 1989. He received the B.Eng. and M.Eng. degrees in electrical engineering, power systems, from Institut Teknologi Sepuluh Nopember (ITS), Surabaya, Indoensia, in 2011 and 2013, respectively.

$\mathrm{He}$ is a lecturer in the Department of Marine Engineering of ITS since 2014 and currently a Ph.D candidate at the Hiroshima University, Hiroshima, Japan. His research interest includes renewable energy systems and control of power converters. One of his publications is entitled A review of solar power boat development which published in IPTEK, vol. 27, no. 1, pp. 1-8, April 2016. He is currently working toward high efficiency maximum power tracking for PV system for ship application.

Mr. Kurniawan is a student member of Institute of Electrical and Electronics Engineers (IEEE). He was an organizing committee of International Conference on Advanced Mechatronics, Intelligent Manufacture, and Industrial Automation which held in Surabaya, October 2015.

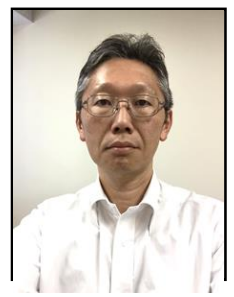

Eiji Shintaku was born in Hyogo, Japan in 1966. He received the B.E., M.E. and Dr. Eng. degrees in naval architect from Kyushu University, Japan, in 1989, 1991 and 1995 , respectively.

$\mathrm{He}$ is an associate professor at the Department of Transportation and Environmental Systems, Hiroshima University, Japan. His research interests include development of structural monitoring devices for large scale structure, control of marine equipment, electric propulsion system for ship.

$\mathrm{He}$ is a member of The Japan Society of Naval Architects and Ocean Engineers, The Japan Institute of Marine Engineering and The Robotics Society of Japan. 